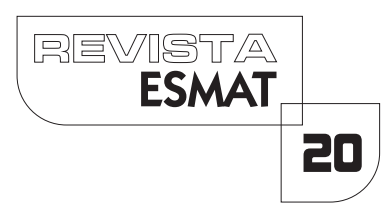

\title{
REDUÇÃO DA MAIORIDADE PENAL: ASPECTOS FAVORÁVEIS, CONTRÁRIOS E ANÁLISE DO SISTEMA ALIENÍGENA
}

\author{
REDUCTION OF THE AGE OF CRIMINAL RESPONSABILITY: FAVORABLE, AND
} OPPOSITE ASPECTS A ANALYSIS OF THE ALIEN SYSTEM

LENIS DE SOUZA CASTRO ${ }^{1}$ MARCELO LAURITO PARO ${ }^{2}$

\section{RESUMO}

A crescente onda de criminalidade fomentou a discussão sobre a redução da maioridade penal, ganhando espaço no meio acadêmico e social. De acordo com o sistema adotado pelo Brasil, os maiores de 12 e menores de 18 anos somente podem responder pelos atos ilícitos praticados nos termos do Estatuto da Criança e do Adolescente, ficando impossibilitada a aplicação da lei penal. O constituinte pressupôs que tais indivíduos não podem ser plenamente responsabilizados por seus atos por não terem o completo desenvolvimento mental. $\mathrm{Na}$ mesma linha, o modelo prisional brasileiro tem demonstrado que a finalidade reeducativa é meramente utópica, devendo-se preferir, segundo alguns, as medidas socioeducativas do sistema menorista. Para a corrente favorável à alteração da maioridade, o estágio de desenvolvimento atual, em contraposição ao vivenciado em 1940 (quando da edição do Código Penal) deve ser levado em conta, por refletir diretamente no grau de compreensão dos adolescentes de hoje. No presente estudo, serão analisados os principais argumentos, favoráveis e contrários à mencionada alteração legislativa, bem como examinados alguns modelos estrangeiros, em especial o adotado no Canadá.

Palavras-chave: Adolescente Infrator. Redução da Maioridade Penal.

\begin{abstract}
The rising tide of crime has encouraged discussion of the reduction of legal age, gaining ground in the academic and social environment. Under the system adopted in Brazil, over 12 and under 18 can only answer for the torts committed under the Statute of Children and Adolescents, being unable enforcement of criminal law. The constituent assumed that such individuals cannot be held fully accountable for their actions for lack of full mental development. In the same vein, the Brazilian prison model has shown that reeducation purpose is merely utopian, should be preferred, according to some, the social and educational measures system. For the favorable current to the change of majority, the current stage of development, as opposed to experienced in 1940 ( when the issue of the Criminal Code) should be taken into account, directly reflect the degree of understanding on today's teenagers.

\footnotetext{
${ }^{1}$ Especialista em Teoria da Decisão Judicial, pela Escola Superior da Magistratura Tocantinense. Especialista em Criminologia e Ciências Criminais, pela Escola Superior da Magistratura Tocantinense. Graduado em Direito, pela Universidade de Uberaba. Técnico Judiciário do Tribunal de Justiça do Estado do Tocantins.

${ }_{2}$ Doutorando em Desenvolvimento Regional, pela Universidade Federal do Tocantins. Mestre em Prestação Jurisdicional e Direitos Humanos, pela Universidade Federal do Tocantins. Especialista em Criminologia e Ciências Criminais, pela Escola Superior da Magistratura Tocantinense. Graduado em Direito, pela Faculdade de Direito de São Bernardo do Campo. Juiz de Direito do Tribunal de Justiça do Estado do Tocantins.
} 
In this study, the main arguments in favor and against the mentioned legislative change will be analyzed and examined some foreign models, especially the one adopted in Canada.

Keywords: Teenage Offender. Reduction of Legal Age.

\section{INTRODUÇÃO}

Os jornais de todo o País noticiaram, em 3 de abril de 2012, que um adolescente de 17 anos, detentor do registro de mais de 120 atos infracionais, atacou uma promotora de justiça com uma tesoura, durante sua audiência. A morte foi evitada pela rápida intervenção do agente penitenciário, do juiz e do próprio advogado do menor (AZEVEDO, 2012).

Cerca de um ano depois, assistimos estarrecidos ao assassinato da dentista Cinthya Magali Moutinho, de 46 anos, em São Bernardo do Campo. A vítima foi queimada viva em seu consultório após os assaltantes receberem a confirmação de que ela possuía apenas R\$ 30,00 (trinta reais) no banco. O fogo foi ateado por um adolescente de 17 anos que, segundo a delegada noticiou à época, relatava o episódio "como se estivesse contando o capítulo de uma novela" (MELO, 2013).

No Tocantins, no mês de julho de 2015, uma criança de sete anos foi estuprada por três adolescentes durante o trajeto do ônibus escolar, enquanto outro adolescente filmava a ação. Todos os infratores tinham entre 14 e 16 anos (REIS, 2015).

Em Campo Grande, um adolescente autor de 4 homicídios, 3 tentativas e diversos roubos afirmou que este é seu modo de aproveitar a vida e que o baixo tempo de privação de liberdade não é suficiente para desestimular os ilícitos (VITORINO).

Fatos como os relatados reforçam a sensação de insegurança da sociedade e reacendem a discussão sobre a opção de o constituinte definir a maioridade penal a partir dos 18 anos. A Constituição Federal, no art. 228, mantém o modelo utilizado desde a edição do Código Penal, em 1940, o que, segundo uma parcela de juristas e da sociedade civil, representaria um sistema desatualizado.

Um segundo grupo, contudo, não acredita que a redução da maioridade seja capaz de solucionar o problema da criminalidade, fundamentando-se na falência do sistema prisional criminal. Este é o objeto do presente estudo, que visa analisar os argumentos de ambas as correntes e traçar um paralelo com o modelo adotado em alguns países, a exemplo do Canadá, os quais se baseiam na personalidade e no desenvolvimento do adolescente, e não meramente na sua idade biológica. 
Para melhor compreensão do tema, faremos inicialmente um breve resumo acerca da sistemática atual de responsabilização dos menores infratores, segundo o ordenamento Brasileiro.

Em seguida, passaremos à análise dos argumentos favoráveis e contrários à modificação da menoridade penal, buscando esclarecer as fragilidades de cada corrente.

Por último, abordaremos o tema sob a ótica da legislação estrangeira, mais especificamente do Canadá, Estados Unidos e alguns países Europeus, visando destacar as vantagens do mencionado sistema.

\section{SISTEMA DE RESPONSABILIZAÇÃO POR ATOS INFRACIONAIS NO BRASIL}

Inicialmente, é necessário compreender o conceito analítico de crime que, ao longo das décadas, tem sido discutido pela doutrina. Prevalece, no Brasil, a utilização do conceito finalista, segundo o qual, o crime seria todo ato típico, ilícito e culpável. Nesse sentido, temos as palavras de Toledo (1994, p. 80):

\footnotetext{
Substancialmente, o crime é um fato humano que lesa ou expõe a perigo bens jurídicos (jurídicos-penais) protegidos. Essa definição é, porém, insuficiente para a dogmática penal, que necessita de outra mais analítica, apta a por à mostra os aspectos essências ou os elementos estruturais do conceito de crime. E dentre as várias definições analíticas que têm sido propostas por importantes penalistas, parece-nos mais aceitável a que considera três notas fundamentais do fato-crime, a saber: ação típica (tipicidade), ilícita ou antijurídica (ilicitude) e culpável (culpabilidade). O crime, nessa concepção que adotamos, é, pois, ação típica, ilícita e culpável.
}

Partindo desse pressuposto, podemos dizer que o fato típico é composto pela conduta, resultado, nexo de causalidade e tipicidade em sentido estrito (englobando a formal e a conglobante). A ilicitude ou antijuridicidade é a ausência do comportamento em estado de necessidade, legítima defesa, estrito cumprimento do dever legal ou exercício regular de um direito. Por último, a culpabilidade analisará a potencial consciência da ilicitude, a exigibilidade de conduta diversa e a imputabilidade (GRECO, 2008, pp. 141-144), sendo este último elemento o que mais nos interessa para o presente estudo.

Conforme afirma Greco (2008, p. 396), "para que o agente possa ser responsabilizado pelo fato típico e ilícito por ele cometido, é preciso que seja imputável". Trata-se, portanto, da capacidade de se atribuir a alguém a prática de um fato típico e ilícito.

Segundo Sanzo Brodt (1996, p. 46), 
A imputabilidade é constituída por dois elementos: o intelectual (capacidade de entender o caráter ilícito do fato), o outro volitivo (capacidade de determinar-se de acordo com esse entendimento). O primeiro é a capacidade (genética) de compreender as proibições ou determinações jurídicas. Bettiol diz que o agente deve poder 'prever as repercussões que a própria ação poderá acarretar no mundo social', deve ter, pois, 'a percepção do significado ético/social do próprio agir'. O segundo, a 'capacidade de dirigir a conduta de acordo com o entendimento éticojurídico'. Conforme Bettiol, é preciso que o agente tenha condição de avaliar o valor do motivo que o impele à ação e, do outro lado, o valor inibitório da ameaça penal.

Mencionada definição de imputabilidade é imprescindível para compreensão do tema que aqui tratamos. O sistema brasileiro definiu dois fatores de exclusão da imputabilidade: por imaturidade psicológica (doença mental ou desenvolvimento incompleto) ou por imaturidade etária.

Quanto ao critério etário, o Código Criminal, de 1830, definia que eram inimputáveis (e, portanto, não poderiam ser responsabilizados por atos típicos e ilícitos) os menores de 14 anos. O de 1890 previa a inimputabilidade absoluta aos menores de 9 anos e relativa aos maiores de 9 e menores de 14 anos, que responderiam nos termos da mencionada lei se demonstrassem discernimento. Ambas as previsões recebiam numerosas críticas em razão dos baixos limites de idade, em especial considerando o desenvolvimento social da época.

Décadas mais tarde, nos termos do art. 228 da Constituição Federal, de 1988, e do art. 104 do Estatuto da Criança e do Adolescente, definiu-se que são penalmente inimputáveis os menores de 18 anos. Não significa, contudo, que sejam absolutamente irresponsáveis por seus atos.

O Estatuto da Criança e do Adolescente conceitua, em seu art. $2^{\circ}$, as duas espécies de sujeitos de direitos, dispondo que adolescentes são indivíduos com idade entre 12 e 18 anos incompletos. A responsabilização por atos análogos a crimes ou contravenções penais é reservada apenas aos integrantes desse grupo (art. 104, parágrafo único, e art. 105, ambos do Estatuto da Criança e do Adolescente).

Praticado o ato infracional, deve ser lavrado o Boletim de Ocorrência Circunstanciado, no bojo do qual serão realizados os atos investigatórios, à semelhança do que ocorre com o Inquérito Policial. A lei dispõe que ao adolescente são asseguradas as mesmas garantias do processo penal (art. 111 do Estatuto da Criança e do Adolescente). Tal ideia é reforçada pela edição da Súmula nº 342 do Superior Tribunal de Justiça ${ }^{3}$.

Presentes indícios de autoria e prova da materialidade, poderá o Ministério Público

\footnotetext{
3 "No procedimento para aplicação de medida socioeducativa, é nula a desistência de outras provas em face da confissão do adolescente".
} 
promover o arquivamento ou oferecer representação. Esta última, a exemplo do que se dá com a denúncia, é a peça inaugural do processo que apurará a responsabilidade do suposto infrator.

O ponto diferenciador do mencionado sistema com o proposto pelo Código de Processo Penal é a possibilidade de o membro do Ministério Público oferecer proposta de remissão. Segundo Veronese e Silveira (2011, p. 389),

\begin{abstract}
O benefício da remissão consiste em uma forma de exclusão do processo e, para concedê-la, o Promotor de Justiça deverá considerar circunstâncias e consequências do ato cometido, bem como o contexto social e a personalidade do adolescente. A remissão não implica no reconhecimento ou comprovação da responsabilidade, nem prevalece para efeito de antecedentes criminais. De acordo com a necessidade, poderá ser concedida cumulativamente com uma ou mais das medidas protetivas previstas no art. 101 do Estatuto, ou uma das medidas socioeducativas do art. 11, exceto a colocação em regime de semi-liberdade e a internação. Registre-se que a remissão deve ser aceita pelo adolescente e seus genitores ou responsáveis.
\end{abstract}

Sendo oferecida a representação, o juiz designará data para a audiência de apresentação do adolescente (art. 184) e após, caso necessário, nomeará advogado para apresentar defesa prévia em três dias, contados da data da audiência. Recebida esta, haverá a designação da audiência de continuação para oitiva da vítima e das testemunhas.

Não havendo a necessidade de outras diligências, será concedida a palavra ao Ministério Público e, em seguida, à defesa para apresentação de alegações finais (orais segundo a literalidade do $\S 4^{\circ}$ do art. 186), proferindo-se a sentença na sequência. Julgada procedente a representação, o juiz aplicará uma das medidas socioeducativas do art. 112: advertência, obrigação de reparar o dano, prestação de serviços à comunidade, liberdade assistida, inserção em regime de semiliberdade, internação em estabelecimento educacional ou qualquer das medidas de proteção do art. 101, incisos I a VI, do mesmo Manual.

Em síntese, o ordenamento jurídico entende que os menores de 18 anos não possuem imputabilidade, que é elemento da culpabilidade e, logo, não estaria completo o conceito de crime. Por tal motivo, apenas responderiam por atos infracionais, submetendo-se a um sistema consideravelmente mais brando.

As críticas ao mencionado modelo ganharam peso nos últimos anos ante a crescente onda de violência juvenil, conforme exposto anteriormente. O tráfico de drogas há muito tempo vem utilizando a mão de obra adolescente, aproveitando-se do fato de serem excelentes escudos aos reais líderes, em razão das baixas punições. Ainda que sejam pegos, logo teriam condições de retornar ao "trabalho".

Como se não bastasse, temos assistido aos noticiários trazendo, diariamente, informações de crimes bárbaros praticados por adolescentes, aliados, ou não, aos adultos. 
Estupros, latrocínios, homicídios qualificados são meros exemplos das atrocidades que temos vivenciado.

Para uma parcela da população, as medidas previstas pelo sistema legislativo nacional a título de sanção não são suficientemente eficazes para reeducar os infratores ou inibir a prática de novos atos. É nesse contexto que surge a defesa da redução da menoridade penal como tentativa de possibilitar que alguns adolescentes, em especial a partir dos 16 anos, pudessem sofrer sanções mais severas, respondendo nos termos da Lei Penal.

Para outros, o problema encontra-se na errônea aplicação das regras de ressocialização. Para esse grupo, dada a conhecida falibilidade do sistema prisional, de nada adiantaria submeter os adolescentes a penas mais longas, cumpridas nos já superlotados presídios. A solução para a crescente onda de violência estaria na fortificação da estrutura de apoio (conselho tutelar, entidades de atendimento, assistência social), paralela à melhora da educação e à estruturação das famílias.

Feitas tais considerações, passamos à análise das propostas de modificação da maioridade penal.

\subsection{Proposta de Alteração do Sistema}

O tema vem sendo discutido no Brasil desde a década de 90, por meio de inúmeras propostas de emenda constitucional. Na Câmara dos Deputados, a Proposta de Emenda Constitucional (PEC) $n^{\circ} 171$, de 1993, conta com 25 propostas apensadas, enquanto que no Senado Federal, a Proposta de Emenda Constitucional (PEC) $n^{0} 26$, de 2002, possui 6 substitutivos.

No Senado, a Proposta de Emenda Constitucional (PEC) $\mathrm{n}^{\circ}$ 74, de 2011, define a imputabilidade a partir dos 15 anos para os crimes de homicídio doloso e roubo seguido de morte. A Proposta de Emenda Constitucional (PEC) n 21 , de 2013, afirma serem plenamente imputáveis os com idade igual ou maior de 15 anos. Já a Proposta de Emenda Constitucional (PEC) $\mathrm{n}^{\circ} 33$, de 2012, aduz que os maiores de 16 e menores de 18 poderão sofrer incidente de desconsideração da inimputabilidade, de iniciativa privativa do Ministério Público e apreciável pelo juízo da Infância e Juventude. O incidente somente seria aplicável aos crimes hediondos e equiparados.

A procedência do pedido de desconsideração da inimputabilidade se dará nas hipóteses de comprovação do caráter ilícito do ato praticado, levando-se em conta todo o 
histórico familiar e social do adolescente. Analisa-se, portanto, se este seria imputável no sentido material (possuidor de razão e volição).

O cumprimento da pena se dará em estabelecimento próprio, diverso daquele destinado aos adultos. Em 20 de agosto de 2015, as primeiras duas propostas foram rejeitadas pela Comissão de Constituição e Justiça, aprovando-se a última.

Ainda em 2007, a Comissão de Constituição e Justiça (CCJ) do Senado aprovou o substitutivo de autoria do então senador Demóstenes Torres, que previa a redução da maioridade para 16 anos, apenas para os crimes hediondos e equiparados, desde que houvesse laudo psicológico demonstrando a plena capacidade de entendimento.

Caso definitivamente aprovada tal proposta, a redação do art. 228 da Constituição Federal passaria a ser a seguinte:

\footnotetext{
Art. 228. São penalmente inimputável os menores de dezesseis anos, sujeitos às normas da legislação especial.

Parágrafo único. Os menores de dezoito e maiores de dezesseis anos:

I - somente serão penalmente imputáveis quando, ao tempo da ação ou omissão, tinham plena capacidade de entender o caráter ilícito do fato e de determinar-se de acordo com esse entendimento, atestada por laudo técnico, elaborado por junta nomeada pelo juiz;

II - cumprirão pena em local distinto dos presos maiores de dezoito anos;

III - terão a pena substituída por uma das medidas socioeducativas, previstas em lei, desde que não estejam incursos em nenhum dos crimes referidos no inciso XLIII, do art. $5^{\circ}$, desta Constituição.
}

Um dos projetos ( $n^{\circ} 171$, de 1993) recentemente foi aprovado na Câmara dos Deputados. Segundo este, os maiores de 16 e menores de 18 que praticarem ato análogo a homicídio doloso, lesão corporal seguida de morte e crime hediondo poderão ser processados nos termos do Código Penal. A sanção, contudo, deverá ser cumprida em estabelecimento diverso do destinado aos menores de 16 e aos maiores de 18 . Sobre esta terceira modalidade de estabelecimento, faremos novas considerações abaixo.

A discussão, no entanto, está longe de terminar. A proposta aprovada pela Câmara seguirá agora para o Senado Federal, onde será votada em dois turnos. Isso sem mencionar os inúmeros outros projetos que aguardam deliberação.

$\mathrm{Da}$ análise das propostas mencionadas, verificamos grandes e relevantes diferenças entre elas, que ocasionaram muitas discussões no cenário legislativo e social. Parece-nos, contudo, que a Proposta de Emenda Constitucional (PEC) no 33, de 2012, do Senado é a que mais se aproxima da ideia defendida no presente artigo. 


\section{ARGUMENTOS FAVORÁVEIS E CONTRÁRIOS À ALTERAÇÃO DA MAIORIDADE PENAL}

\subsection{Argumentos Favoráveis}

Inicialmente, deve-se compreender que a modificação da atual sistemática da maioridade penal implicaria, invariavelmente, a modificação da própria Constituição, em seu art. 228. A professora Maria Garcia defende tal possibilidade, argumentando que é a Constituição quem "sujeita os menores de 18 anos às normas da legislação especial, abrindo exceção, portanto, à própria regra" (GARCIA, p. 265). Este é também o entendimento do professor Nucci (2000, p. 109).

No atual modelo, os adolescentes praticantes dos mais graves atos infracionais, como estupro, homicídio qualificado, tortura, tráfico de drogas, dentre outros, submetem-se, via de regra, à internação. Esta é a mais grave medida socioeducativa prevista no art. 112 do Estatuto da Criança e do Adolescente, tendo duração mínima de 6 meses. Após esse período, o adolescente será avaliado por equipe multidisciplinar que, caso necessário, poderá sugerir a manutenção da medida por igual período, desde que não ultrapasse o lapso de 3 anos.

É este o tempo, portanto, que um adolescente de 17 anos que mata, de modo cruel, um semelhante, terá a liberdade restringida, enquanto que aos maiores de 18 o Código Penal reserva a pena mínima de 12 anos (art. 121, § 2 , inciso III, Código Penal Brasileiro (CPB)).

Não bastasse a desproporção das sanções, devemos considerar que os centros de internação de adolescentes são, em sua grande maioria, absolutamente impróprios aos fins educacionais visados pelo Estatuto da Criança e do Adolescente. O Conselho Nacional de Justiça divulgou o Relatório Final do Programa Justiça ao Jovem, referente ao período de julho de 2010 a outubro de 2011, apontando diversos problemas encontrados nas unidades de internação de todo o País, como: falta de apoio dos Governos Estaduais; incapacidade pessoal dos gestores das unidades; insuficiência de atividades pedagógicas, profissionalizantes e de atendimento psicológico e social dos adolescentes e suas famílias; ausência de uniformidade nos procedimentos para a execução das medidas socioeducativas.

O Conselho Nacional do Ministério Público também divulgou relatório dos dados colhidos nos anos 2012 e 2013 constatando o seguinte:

f) No quesito salubridade, a situação mais crítica, com comprometimento das unidades por falta de higiene, conservação, iluminação e ventilação adequadas, foi 
verificada nos Estados do Piauí, Roraima e Sergipe, onde a totalidade das unidades foram consideradas insalubres. Os índices de insalubridade: Paraíba (80\%), Goiás $(85,7 \%)$, Pará $(75 \%)$, Rio de Janeiro $(71,4 \%)$, Mato Grosso $(75 \%)$, sendo que o melhor quadro está em São Paulo e Ceará, onde 91,3\% e 89,9\% foram consideradas salubres, respectivamente. Em síntese, o Centro-Oeste, Nordeste e Norte, mais da metade foram consideradas insalubres; no sul, $40 \%$ foram reprovadas. A melhor situação é do Sudeste, com $77,5 \%$ de unidades salubres. g) Quanto às salas de aula adequadas, o Sudeste conta com $82,9 \%$; o Norte com $72,5 \%$, tendo gravitado entre $52 \%$ e $56 \%$ nas regiões Centro-Oeste, Nordeste e Sul ${ }^{4}$.

O relatório também apontou as deficiências na estrutura física e de pessoal. É certo, portanto, que os estabelecimentos destinados à internação dos adolescentes infratores encontram-se no mesmo ou em pior estado que as unidades prisionais, fazendo cair por terra o argumento de que enviar adolescentes à cadeia seria o mesmo que matriculá-los na faculdade do crime. Pelo que indicam os relatórios acima mencionados, os centros de internação conferem-lhes o mesmo tipo de "educação".

\begin{abstract}
Não serão cordeiros com lobos, e nessa mesma alegação indago qual o maior poder prejudicial, este salientado ou estes mesmos jovens criminais de 16 a 18 em contato com crianças de 10 a 15 anos que ainda tem uma grande chance de recuperação, com seus delitos menores, sendo influenciados, intimidados e até coagidos pela delinquência dos mais experientes que estão na faixa dos 16 a 18 anos e com grande certeza tem uma vasta atividade de infrações, como foi o caso conhecido do jovem vulgo Champinha (CAPUANO).
\end{abstract}

Interessante registrar, como corrente intermediária entre a redução da maioridade penal ou sua manutenção no patamar atual, o posicionamento de Gomes e Bianchini (2007, p. 8). Segundo os autores, embora o sistema prisional seja ineficaz para a solução da violência juvenil, por não cumprir os objetivos ressocializantes, não se pode negar que a previsão de no máximo 3 anos de internação para adolescentes que cometem ilícitos cercados de requintes de crueldade é deveras insuficiente.

Dessarte, defendem a alteração do sistema legislativo para permitir que, nesses casos, os adolescentes sejam submetidos a período maior de privação de liberdade, em estabelecimentos adequados à sua faixa etária. Não seriam, pois, sujeitos à aplicação da lei penal, mas sim do próprio Estatuto da Criança e do Adolescente, ressaltando-se a possibilidade de prazo maior de subsunção às suas regras repressivas.

Atendendo aos interesses desta última corrente, há um Projeto de Lei de autoria do senador José Serra, já aprovado pelo Senado e encaminhado para votação na Câmara dos Deputados, prevendo prazo de até 10 anos de internação para os adolescentes que tiverem praticado ato análogo a crime hediondo (Projeto de Lei no 333, de 2015).

${ }^{4}$ Relatório mostra superlotação nas unidades de internação para adolescentes. 
Proposta muito semelhante, prevendo prazo máximo de internação de 8 anos para atos infracionais análogos a crimes hediondos foi feita pelo governador Geraldo Alckmin (Projeto de Lei ${ }^{\circ}$ 7.197, de 2002), ainda aguardando deliberação da Câmara.

Contudo, talvez o maior argumento dos defensores da modificação da maioridade penal resida no fato de que o critério etário adotado pela Constituição Federal e pelo Código Penal não se funda em nenhuma razão de ordem científica. Trata-se de mera escolha de política criminal. Necessitava-se de um parâmetro a partir do qual se distinguiriam os infratores dos criminosos - o décimo oitavo aniversário foi o escolhido.

A justificativa para tal diferenciação é o fato de o adolescente ser pessoa em desenvolvimento, devendo ser tratado como tal. Contudo, adota-se um sistema em que o desenvolvimento não é analisado em momento algum. Não há, no plano fático, nenhuma mudança no desenvolvimento psíquico ou social do adolescente durante a noite que separa os 17 dos 18 anos.

Nada semelhante à metamorfose da borboleta que se opera. Portanto, uma única noite separa, apenas ficticiamente, o indivíduo desenvolvido (que responde pelos altos rigores do Código Penal) do não desenvolvido (sujeito às benesses do Estatuto da Criança e do Adolescente). Isso se dá pela mera vontade do Constituinte.

Todos os exemplos citados anteriormente, durante a introdução, tratam de atos ilícitos praticados por adolescentes que tinham, provavelmente, total consciência do que faziam e todas as condições de se determinarem conforme suas vontades (critérios da imputabilidade).

Nessas condições, todas as atrocidades teriam sido praticadas por mero desprezo da lei, por sujeitos que se beneficiaram das baixas sanções do Estatuto da Criança e do Adolescente e, após, darão prosseguimento na empreitada delitiva.

\subsection{Argumentos contrários}

Acerca do que foi afirmado ao final do tópico anterior, é sabido que a adolescência é um período de profundas mudanças neurológicas, que influenciam diretamente $o$ comportamento dos indivíduos. A ciência tem demonstrado que algumas regiões do cérebro, como córtex pré-frontal, somente atingem seu completo desenvolvimento entre os 25 e 27 anos (HECKE, 2013).

Tem-se afirmado que por volta do décimo oitavo aniversário ocorreria a poda sináptica no cérebro do humano. Nesse período, o sistema neurológico eliminaria grande 
parcela de conexões e fortaleceria outras (RAEBURN, 2007). Sendo assim, este seria um período em que o adolescente estaria propenso a novos estímulos (que poderiam influenciar seu comportamento futuro), bem como seu completo desenvolvimento neurológico.

Segundo essa linha de pensamento, a responsabilização penal dos menores de 18 anos não seria possível porque somente nesta faixa etária é que o desenvolvimento neural estaria completo. Esse argumento, contudo, encontra seu ponto frágil no próprio desenvolvimento da ciência que, conforme visto, mais recentemente tem apontado que algumas áreas do cérebro humano somente se desenvolveriam completamente após o vigésimo quinto aniversário.

Outro argumento invocado pelos críticos da proposta de redução da maioridade penal é no sentido de que a medida feriria o princípio da proteção integral à criança e ao adolescente. Assim, a definição de adolescente como pessoa com idade entre 12 e 18 anos e a organização de um sistema próprio para correção de condutas desviadas funcionariam como verdadeira garantia.

Segundo esse ponto de vista, a não incidência da lei penal aos menores de 18 anos seria uma cláusula pétrea, insuscetível, portanto, de mudança por emenda constitucional. É o entendimento de Fábio Rocha Calliari, segundo o qual "o artigo 228 da CF é um direito individual, concretizado no princípio da dignidade da pessoa humana. É uma liberdade negativa face ao Estado, e, portanto, uma cláusula pétrea, cuja redução não pode operar por meio de Emenda à Constituição" (CALLIARI, 2008, pp. 174-188). No mesmo sentido, é o entendimento de Silva (2006).

Posto isso, independentemente do atual estágio de desenvolvimento social e do grau de compreensão dos adolescentes de hoje ou do futuro, enquanto vigente o sistema constitucional definido em 1988, jamais se poderia cogitar na responsabilização penal da pessoa com menos de 18 anos.

Tal ideia é inconcebível a nosso ver. Nota-se, em primeiro lugar, que nenhuma garantia (nem mesmo o direito à vida) é absoluta; o mesmo devendo ser dito em relação ao princípio da proteção integral. Em segundo lugar, a definição da mencionada norma como cláusula pétrea não é expressa, tratando-se de mera suposição por parte dos seus defensores. Esse foi, aliás, o entendimento da Comissão de Constituição e Justiça do Senado ao aprovar a Proposta de Emenda Constitucional (PEC) n ${ }^{\circ} 33$, de 2012, outrora mencionada.

Ademais, conforme exposto anteriormente, não se pode cogitar que o grau de desenvolvimento psicológico e social de um adolescente nos dias de hoje seja o mesmo de quase trinta anos atrás (quando da edição da Constituição), ou será o mesmo daqui a dez anos. 
Estabelecer uma regra cega (nenhum adolescente com menos de 18 anos completos é capaz de compreender a gravidade e ilicitude dos atos que pratica) é fechar os olhos para a realidade, engessar o sistema jurídico e deixar ao léu uma segunda garantia constitucional: a segurança pública.

Sobre o tema, salutares são as palavras de Cavalcanti (2013, pp. 117-134):

Destaca-se, ainda, que essa defesa da fixação dos 18 anos como um marco mágico da inimputabilidade não tem amparo científico, não representa uma verdade reconhecida no âmbito das organizações internacionais, não foi agasalhada pela Unicef, que apenas recomenda a definição da idade penal mínima com base em critérios científicos. [...] Em verdade, o limite de inimputabilidade de 18 anos não é consagrado, na grande maioria dos sistemas jurídicos hoje vigentes.

Nota-se que não se cogita a responsabilização criminal de um incapaz, mas sim de um indivíduo que, embora menor de 18 anos, tenha plena capacidade de compreensão dos atos que pratica, evitando-se que seja beneficiado por um critério estabelecido sem fundamento científico.

Um terceiro argumento seria o de que as medidas socioeducativas, quando bem aplicadas, alcançam o efeito socializador e educativo esperado. O professor Tavares (2013), em palestra proferida no auditório do Superior Tribunal de Justiça, afirmou:

O confinamento de adolescentes envolvidos em atos violentos não irá implicar a diminuição do número de infrações, irá apenas satisfazer sentimentos de vingança. Referindo-se ao ECA, arrematou: para menores infratores, sugiro mais assistência, mais educação, mais recuperação, mais estatuto e menos Código Penal.

O problema dessa afirmação repousa no fato de que apenas uma pequena parcela das medidas são bem aplicadas e dependem, principalmente, da vontade do próprio adolescente em abandonar a carreira delitiva.

Tratando mais de perto da realidade do Tocantins, o que vemos são comarcas desprovidas de estrutura para proporcionar a correta e adequada aplicação, por exemplo, da medida de prestação de serviços à comunidade. Liberdade assistida é algo, na maioria das vezes, absolutamente utópico, em especial por falta de profissionais capacitados e em número suficiente.

Se olharmos para os Conselhos Tutelares (integrantes da rede de atendimento) da maior parte dos municípios do interior do Estado, veremos entidades com parcos recursos e, principalmente, pessoas que, apesar da boa vontade, não têm o necessário conhecimento jurídico e psicossocial para enfrentar a situação encontrada. Isso tudo sem mencionarmos o 
caos do sistema público de educação e a costumeira falta de estrutura que assola as famílias brasileiras.

Teles aponta a deficiência econômica, social e familiar para justificar a ineficácia do sistema de responsabilização juvenil, entendendo ser este um argumento que impossibilita o endurecimento do sistema:

\begin{abstract}
Ora, se uma criança se encontra dentro de um ambiente de carência material e espiritual, alijada do acesso a seus direitos fundamentais, sendo envolta no triste quadro da pobreza, ignorância, falta de oportunidades, desagregação familiar, ausência de perspectiva de futuro, por óbvio que a probabilidade de sua absorção pelo mundo do crime cresce exponencialmente. Desse modo, o erro em considerar que o endurecimento das penas ou a ampliação da imputabilidade penal para atingir adolescentes com idade entre 16 e 18 anos resolveria o drama da violência social consiste no desconhecimento de que o direito foi forjado para ser aplicado de forma integral e não parcial, ou seja, somente um Estado que garante a todos a preservação concreta e efetiva da dignidade da pessoa humana, dando aos indivíduos condições de desenvolverem com plenitude as suas potencialidades, pode a posteriori punir o cidadão que delinqui. É justamente aqui que reside a perversidade do Estado brasileiro: ele exclui socialmente, depois reprime (TELLES, 2015).
\end{abstract}

No nosso entender, tal pensamento desconsidera fatores de extrema relevância, em que pese ao brilhantismo de seu autor. O primeiro deles é que os problemas sociais, econômicos e de desestruturação familiar não são de fácil solução, dependendo de uma infinidade de medidas que, se bem executadas, surtirão efeitos em longo prazo. Falamos da melhoria da educação e da saúde (que depende de altos gastos do Governo), redução/fim do desemprego (decorrência lógica da melhoria da economia do País e aumento dos investimentos), dentre outras mudanças sociais que, provavelmente, refletiriam na melhor estruturação das famílias.

Considerando a realidade atual do Brasil, o que se vislumbra é um cenário de pouca (ou nenhuma) possibilidade de ocorrência dessas mudanças em nível suficiente para surtir o efeito esperado, ao menos pelas próximas décadas. Até lá, a problemática da violência juvenil continua crescendo e demanda medida urgente.

O segundo aspecto relevante a ser considerado sobre o pensamento acima transcrito diz respeito à sua perfeita subsunção ao sistema penal de repressão. Se o indivíduo adolescente que se desenvolve em um modelo de desrespeito aos seus direitos fundamentais não pode ser punido severamente pelos atos ilícitos que pratica, o mesmo deve ser dito sobre o indivíduo adulto. Viveríamos, então, em um sistema de completo caos, em que mais da metade da população (que vive sem as mencionadas condições mínimas de dignidade) teria permissão para praticar crimes, sem que nada pudesse ser feito. 
É certo que, na teoria, o sistema previsto pelo Estatuto da Criança e do Adolescente é ótimo e possui grandes possibilidades de bons resultados, se aplicado no âmbito de um modelo social ideal. É na prática que reside o problema, é também nesta que os atos infracionais são praticados, e a população é posta em risco. Cumpre, então, questionar até quando permaneceremos aguardando que o Estado crie os instrumentos necessários ao bom funcionamento do sistema, agarrando-nos ao fato de possuirmos um método que é capaz de reeducar em abstrato, embora falhe veementemente em concreto.

Um terceiro argumento contrário à mudança parece ter sido levado em consideração na elaboração do Projeto de Lei $\mathrm{n}^{\circ}$ 171, de 1993, aprovado em primeiro turno na Câmara dos Deputados, ao determinar que os adolescentes maiores de 16 anos, julgados por crimes graves, deverão cumprir a pena em estabelecimento a ser criado, diverso daquele destinado aos adultos e aos demais jovens sujeitos ao regime descrito no Estatuto da Criança e do Adolescente.

Assim dispondo, ficaria sanado o alegado risco de colocar jovens em "faculdades do crime". De outro modo, demandaria gastos de recursos públicos para a criação dessas entidades - provavelmente iguais ou inferiores aos que seriam decorrentes da construção ou ampliação dos presídios já existentes para abrigamento dos adolescentes condenados, considerando a atual situação de superlotação.

Alguns opositores da ideia têm afirmado ser impossível a criação de uma terceira espécie de estabelecimento, devendo os adolescentes se submeterem à pena (cumprida em penitenciária comum) ou às medidas socioeducativas. Não vemos de tal forma. Nada impede que o Poder Constituinte reformador disponha sobre um novo estabelecimento para cumprimento de pena, voltado para adolescentes que tenham praticado crimes graves e venham a ser julgados nos termos do Código Penal.

Tal medida, aliás, visa garantir a própria condição de pessoa em desenvolvimento, satisfazendo os ideais de proteção integral. Ademais, a ideia de individualização da pena com base na idade e na personalidade do agente não é noção inédita no ordenamento (art. $5^{\circ}$ da Lei de Execuções Penais).

Moraes (2000, p. 244), ao tratar das regras internacionais de proteção aos direitos dos reclusos, afirma que a Organização das Nações Unidas (ONU) prevê a necessidade de separação dos reclusos em diversas categorias, levando em consideração a idade, o sexo, os antecedentes penais e as medidas necessárias a aplicar.

Um último grupo defende, ainda, que a redução da maioridade penal seria reflexo de um pensamento discriminante e elitista, o qual visaria atingir os adolescentes 
economicamente desfavorecidos. Novamente, não encontramos razão. O que se propõe é a aplicação do sistema penal a uma parcela dos adolescentes infratores - sistema este que vige tanto para ricos quanto para pobres.

É certo que estatisticamente, a maior parte dos delitos é praticada por pessoas de classes econômicas inferiores, a exemplo dos crimes contra o patrimônio e tráfico de drogas. Não se pode imputar tal fato, contudo, à vontade da "elite opressora".

\section{MAIORIDADE PENAL NA LEGISLAÇÃO ALIENÍGENA ${ }^{5}$}

No Canadá, a responsabilidade começa aos 12 anos, assim como no Brasil, podendo sofrer a incidência da legislação penal a partir dos 14 anos quando praticados delitos de extrema gravidade, sendo julgados pela Justiça Comum. O mesmo se dá na Dinamarca, a partir dos 15 anos.

Os Estados Unidos da América possuem, em algumas unidades federativas, um sistema, segundo o qual, a partir de 12 anos o adolescente pode ser julgado da mesma forma que os adultos, desde que comprovada a capacidade de entendimento, podendo sofrer até mesmo prisão perpétua e pena de morte.

Na mesma linha, na França vige a presunção relativa de irresponsabilidade penal dos adolescentes com idade entre 13 e 18 anos. Praticado o crime e demonstrada a capacidade de discernimento, é julgado como adulto, recebendo o adolescente, de até 16 anos, redução obrigatória da pena. Nos demais casos, a redução é facultativa.

Na Rússia, a maioridade tem início aos 14 anos para os crimes graves e aos 16 para os demais. Na Inglaterra, a menoridade penal é quase metade da nossa. Suécia e Noruega, dois modelos mundiais de políticas menoristas, adotam a maioridade aos 15 anos.

É certo que a maioria dos países do mundo caminha na contramão da redução da menoridade penal. A Alemanha, por exemplo, voltou a fixá-la em 18 anos, e o Japão a definiu em 20. É impossível, no entanto, comparar tais modelos com o do Brasil, em razão, principalmente, da enorme diferença dos níveis de desenvolvimento social.

Em nosso ordenamento, um adolescente maior de 16 anos é capaz de dispor, sem assistência, de seu patrimônio por testamento, reconhecer paternidade, exercer atividade empresarial (quando emancipado), votar, dentre outros comportamentos. Ele não pode,

${ }^{5}$ Dados constantes da Tabela elaborada pela Unicef. Disponível em: <www.crianca.mppr.mp.br/modules/conteudo/conteudo.php?conteudo=323>. Acesso em: 25 out. 2015. 
contudo, responder criminalmente por matar outra pessoa, independentemente do grau de compreensão que apresente. Não há lógica neste modelo.

Destaca-se que uma das críticas ao sistema atualmente adotado (puramente etário), reside no fato de que o critério de definição da maioridade aos 18 anos não possui fundamentação científica. Não analisa, pois, o perfil psicológico do agente.

Um dia antes do décimo oitavo aniversário, o sujeito responderá por seus atos nos termos do Estatuto da Criança e do Adolescente (ECA), como se deu no caso do adolescente do Distrito Federal que matou a ex-namorada com um tiro na cabeça (GALVÃO, 2013). No dia seguinte, o mesmo ato será atingido por todo o rigor do Código Penal. Não se examina, por conseguinte, o grau de desenvolvimento ou a capacidade de compreensão.

Nesses termos, alguns modelos alienígenas, em especial o do Canadá, mostram-se mais coerentes, ao definir que, em crimes mais graves, o agente poderá vir a responder com mais rigor, desde que demonstrada, no entanto, sua capacidade de compreensão e vontade.

\section{CONSIDERAÇÕES FINAIS}

De tudo quanto exposto anteriormente, conclui-se que os argumentos favoráveis e contrários à alteração da maioridade penal no Brasil não se eliminam (ou ao menos não deveriam).

É certo que se o Estado garantisse melhores condições sociais, em especial de emprego e educação, muitas crianças e adolescentes teriam condições de crescer em um ambiente mais adequado ao seu desenvolvimento, afastando-se da criminalidade. E é igualmente certo que é dever de a sociedade cobrar tal postura de seus governantes. A estruturação das famílias é outro fator relevante ao desenvolvimento dos indivíduos; porém, atualmente, tem estado ausente.

É sabido, ainda, que a correta aplicação e execução das medidas socioeducativas pode alcançar bons resultados, permitindo ao adolescente infrator a reinserção no meio social e a perfeita correção de comportamentos desviados. O sistema previsto pelo Estatuto da Criança e do Adolescente sofre da crise da ineficácia (comum a tantos institutos do ordenamento jurídico). Embora preveja medidas que, em abstrato, teriam totais condições de revolucionar a vida do adolescente infrator, na prática, deixam muito a desejar.

Ao contrário do que alguns defendem, no entanto, essas premissas não excluem ou interferem na necessidade de se discutir a mudança do tratamento da menoridade penal, 
porque, mesmo no mais desenvolvido dos países, sempre haverá, embora em menor escala, violência infantojuvenil.

Acreditamos que todos esses fatores mencionados (melhora das condições sociais, correta execução das medidas socioeducativas e mudança do tratamento jurídico penal) são salutares e devem ser aplicadas conjuntamente, em especial considerando o largo período de tempo necessário à implementação e à eficácia das duas primeiras, por dependerem de altos gastos orçamentários no primeiro caso, e, no segundo, de uma mudança de percepção e postura da própria sociedade.

Até que tais mudanças sociais sejam feitas, deve ser adotada alguma medida de ordem emergencial para conter a violência juvenil e conferir à sociedade, um mínimo de segurança. É nesse cenário que a redução da maioridade penal passa a ter função relevante e, apesar de algumas críticas, plenamente possível de ser aplicada de modo eficaz.

Defendemos que qualquer sistema que defina apenas regras estáticas quanto à idade mínima para responsabilização penal será suscetível a equívocos. Isso porque a capacidade de compreensão da ilicitude dos próprios atos deve ser apurada casuisticamente, analisando-se o grau de desenvolvimento de cada adolescente.

Conforme demonstrado pela vivência no cenário jurídico, é possível que um adolescente de 16 anos tenha total compreensão do que faz, podendo determinar-se livremente de acordo com sua vontade. Doutro modo, este fato não pode ser tomado como regra absoluta aplicável a todas as pessoas da mesma idade.

Ora, a lógica do sistema atualmente adotado funda-se no fato de que os adolescentes, por serem pessoas em desenvolvimento, devem receber tratamento diferenciado quando praticarem os chamados comportamentos desviados. O que não se compreende, contudo, é que um único minuto, que separa a véspera do décimo oitavo aniversário deste adolescente possa ser o divisor de água entre um indivíduo desenvolvido e um não desenvolvido.

Preferível, portanto, a aplicação de um sistema inspirado, por exemplo, no modelo canadense, definindo-se uma regra absoluta para a maioridade penal (são imputáveis os maiores de 18 anos) e uma relativa (os maiores de 16 e menores de 18 poderão responder criminalmente quando praticarem crimes graves - definidos em lei - e ficar demonstrada sua capacidade de compreensão e vontade).

O presente texto não tem a pretensão de esgotar as discussões sobre a problemática da redução da maioridade penal, mas não podemos fechar os olhos para a realidade com a crença de que o modelo previsto pelo Estatuto da Criança e do Adolescente (ECA) seja autossuficiente, pois, como demonstrado, funciona apenas na teoria, enquanto que na prática se mostra absolutamente falido. 


\title{
REFERÊNCIAS
}

\begin{abstract}
AZEVEDO, Lucas. Menor com 120 passagens pela polícia ataca promotora com tesoura em audiência no RS. Disponível em: <noticias.uol.com.br/cotidiano/ultimasnoticias/2012/04/03/menor-com-120-passagens-pela-policia-ataca-promotora-com-tesouraem-audiencia-no-rs.htm>. Acesso em: 27 out. 2015.
\end{abstract}

BASTOS, Celso. Curso de direito constitucional. 19. Ed. São Paulo: Saraiva, 1998.

BATISTA, Carlos Ferraz. Crime, castigo e a Maioridade Penal. São Paulo: Cabral Editora e Livraria Universitária, 2008.

BIANCHINI, Alice; GOMES, Luiz Flávio. Maioridade Penal e o Direito Penal Emergencial e Simbólico. Academia de Direito. São Paulo, maio de 2007.

CALliari, Fábio Rocha. A Menoridade Penal na Constituição Federal. Disponível em: IASP/CNA; GOUVEIA, Carlos Marcelo; HOFFMAN, Luiz Augusto A. (org.). Atual Panorama da Constituição Federal. 1. Ed. São Paulo: Saraiva, 2008.

CAPUANO, Thiago. Redução da maioridade e imputabilidade penal. Disponível em: $<$ http://thiago.capuano.etc.br/>. Acesso em: 12 dez. 2015.

CAVALCANTI, Francisco de Queiroz Bezerra. Considerações acerca da Redução da Maioridade Penal. Revista dos Tribunais Nordeste. Vol. 2/2013, p. 117-134.

CONSELHO NACIONAL DE JUSTIÇA. Panorama Nacional: A execução das medidas socioeducativas de internação. Disponível em: <http://www.cnj.jus.br/sistema-carcerario-eexecucao-penal/programa-justica-ao-jovem>. Acesso em: 10 set. 2015.

CUNHA, Rogério Sanches; LÉPORE, Paulo Eduardo; ROSSATO, Luciano Alves. Estatuto da Criança e do Adolescente Comentado Artigo por Artigo. 6. Ed. São Paulo: Editora Revista dos Tribunais, 2014.

ELIAS, Roberto João. Comentários ao Estatuto da Criança e do Adolescente. São Paulo: Saraiva, 2010.

GALVÃo, Matheus. Adolescente mata ex, um dia antes de completar 18 anos. Disponível em: <galvomatheus.jusbrasil.com.br/noticias/113959883/adolescente-mata-ex-um-dia-antesde-completar-18-anos>. Acesso em: 27 out. 2015.

GARCIA, Maria. Juventude e Violência: a maioridade penal e a ética da responsabilidade. Revista de Direito Constitucional e Internacional, vol. 62, p. 240-270. São Paulo: Revista dos Tribunais, 2008.

GOMES, Luiz Flávio. Maioridade Penal, o ECA e a Razoabilidade. Revista Jurídica

Consulex, São Paulo, n. 166, dez. 2003.

GRECO, Rogério. Curso de direito penal - parte geral. $10^{\mathrm{a}}$ ed. Rio de Janeiro: Impetus, 2008. 
HECKE, Caroline. Psicólogos afirmam que a adolescência vai até os 25 anos. Disponível em: $\quad<$ http://www.megacurioso.com.br/medicina-e-psicologia/39193-nova-orientacao-parapsicologos-diz-que-adolescencia-vai-ate-os-25-anos.htm>. Acesso em: 12 dez. 2015.

LÉPORE, Paulo Eduardo; RAMIDOFF, Mário Luiz; ROSSATO, Luciano Alves. Estatuto da Juventude Comentado. Lei 12.852/13. São Paulo: Saraiva, 2014.

MELO, Débora. Assaltante que ateou fogo em dentista é menor de idade, diz delegada. Disponível em: <noticias.uol.com.br/cotidiano/ultimas-noticias/2013/04/27/assaltante-queateou-fogo-em-dentista-e-menor-de-idade-diz-delegada.htm>. Acesso em: 27 out. 2015.

MENDES, Gilmar Ferreira. Curso de direito Constitucional. 7. Ed. São Paulo: Saraiva, 2012 .

MORAES, Alexandre. Direito Constitucional. 6. ed. São Paulo: Atlas, 2000.

NUCCI, Guilherme de Souza. Código Penal Comentado. São Paulo: Editora Revista dos Tribunais, 2000.

RAEBURN, Paul. Tradução de Frances Jones. Entre riscos e benefícios. O uso continuado de antidepressivos por crianças e adolescentes pode levar a alterações imprevisíveis na química e na estrutura cerebral. Duetto editoria, edição 176, set. 2007. Disponível em: $<$ http://www2.uol.com.br/vivermente/reportagens/entre_riscos_e_beneficios.html $>$. Acesso em: 23 dez. 2015.

REIS, Patrício. Adolescente acusados de estupro em ônibus escolar são condenados. Disponível em: <g1.globo.com/to/Tocantins/noticia/2015/10/adolescentes-acusados-deestupro-em-onibus-escolar-são-condenados.html>. Acesso em: 27 out. 2015.

SANZO BRODT, Luís Augusto. Da consciência da ilicitude no direito penal brasileiro. Belo Horizonte: Del Rey, 1996.

SILVA, José Afonso da. Comentário Contextual à Constituição. 2. Ed. São Paulo: Editora Revista dos Tribunais, 2006.

SUPERIOR TRIBUNAL DE JUSTIÇA. Menores infratores merecem mais ECA e menos Código Penal, diz Juarez Tavares. Disponível em: <http://stj.jus.br/portal_stj/publicacao/engine.wsp?tmp.area=398\&tmp.texto=112695>.

TELLES, Lucio Feres da Silva. A intangibilidade da maioridade penal estabelecida na Constituição de $1988 . \quad$ Disponível em: <dspace.almg.gov.br/xmlui/handle/11037/19500?show=full>. Acesso em: 25 out. 2015.

TOLEDO, Francisco de Assis. Princípios básicos do direito penal. São Paulo: Saraiva, 1994.

VERONESE, Joseane Rose Petry; SILVEIRA, Mayra. Estatuto da Criança e do Adolescente comentado. São Paulo: Conceito Editorial, 2011

VITORINO, Paula. Adolescente que matou 4 diz que pena para menor é muito branda. Disponível em: <http://www.amambainoticias.com.br/policia/adolescente-que-matou-4-dizque-pena-para-menor-e-muito-branda>. Acesso em: 3 nov. 2015.

Recebido em: 05/09/2019

Aprovado em: 20/05/2020 